\title{
Severe personality disorder in the secure estate: continuity and change
}

\author{
Paul Taylor
}

\begin{abstract}
The Response to Offender Personality Disorder Consultation was released in October 2011. For some this is a welcome step in the right direction due to its therapeutic optimism, however for practitioners operating in the secure estate there are significant challenges ahead. This aim of this article is to discuss the increasing convergence of health and criminal justice and their inherent ideological and practical difficulties. It does so with reference to the consultation on offender personality disorder pathways and in particular the implications regarding multi-disciplinary and cross agency approaches to risk, public protection and personality disorder respectfully. It concludes that before embarking on a new wave of determining and responding to those with personality disorder, offender or otherwise, a more in-depth and empirically informed critical reflection is warranted.
\end{abstract}

On 21 October 2011, the Department of Health (DH) released its response to a consultation on offender personality disorder pathways completed in May 2011.1 The joint response by the DH and National Offender Management Service (NOMS) offender personality disorder team signals a re-configuration of services for offenders with personality disorder across the secure estate, with a particular focus on the gradual decommissioning of Dangerous Severe Personality Disorder (DSPD) pilot sites in National Health Service (NHS) Secure Hospitals. It is anticipated that the savings made on such units can be effectively re-distributed into robust services for severe personality disorder (SPD). In a written ministerial statement to the House of Commons, Minister of State for Care Services Paul Burstow announced a re-organization of services that allowed for interventions and treatments to be provided earlier, that they take place in the most suitable locations and an enhancement of ongoing supervision.2

The DSPD programme was conceived under New Labour proposals and represented a significant alliance being formulated between health-care and criminal justice agencies. Around 300 DSPD beds were commissioned across two secure hospitals and two prison sites in England and Wales. A therapeutic optimism began to pervade political and professional discourses surrounding risk and public protection; however, as several authors report,3,4 some disquiet emerged over the responsibilities and abilities of psychiatry and psychology to successfully treat personality disorders.

Strategies for tackling 'risky' populations had seen significant shifts over the course of New Labour's initial and successive term in office, with a definite focus on alleviating the potential threat to the public through a range of innovative legislations. Developing simultaneously in the spheres of criminal justice and medicine, the definition, recognition and effective response to the dangerous offender became of paramount importance. Risk to the public was no longer being tolerated and as Rutherford5 (pp. 85-86) suggests, '[DSPD] proposals might be viewed as a bellwether for a wide-ranging transformation of criminal justice'.

The first decade of the 21 st century also witnessed the rhetorical figure of the dangerous offender becoming evermore pronounced in criminal justice policy. Section 229 of the Criminal Justice Act (2003) provides criteria for the assessment of dangerousness for criminal offences in relation to perceived risks that the offender is viewed to pose. However, as Harrison6 notes, the label of the dangerous offender is temporal and has experienced a range of offences falling under its guise such as burglary, repeat offenders and more recently violent and sexual crimes committed by individuals who fall within and outside of official diagnoses. Much like the DSPD programme, the formalizing of Multi Agency Public Protection Arrangements and the introduction of Indeterminate Sentences for Public Protection under the Criminal Justice Act (2003) provides illustrations of the responses parliamentarians and professionals have designed in order to satisfy the demands of a risk-intolerant society.

The discursive wrangling of risk and public protection have taken their toll on those involved in administering such processes. Indeed, therapy has gained greater credence in the processing of the dangerous offender. However, the juncture of actuarial practices and clinical interventions has left some with a challenging responsibility. Addressing offending behaviour via a therapeutic approach is nothing new, and even before the commissioning of the DSPD programme, Rose raised caution that for the psychiatric profession, their role has become increasingly administrative by way of a responsibility to manage problematic persons in a bid to control their future conduct.

The role of the DSPD programme has not solely been concerned with public protection; on the contrary, a key facet of these pilot sites has been to assess and treat offenders meeting the relevant assessment criteria. Consistent with a medical and scientific basis, several clinical assessment tools have been employed such as the Hare Psychopathy Checklist-Revised (PCL-R) and Violence Risk Appraisal Guide to name but a few. However, making predictions of behaviours based upon rigid and scientific assessments, as Seddons posits, provides potential for failures. This can be observed in two ways: firstly, through a critical lens that assimilation into such a programme may reinforce potentially damaging stigmatization, and secondly, that exclusion from a programme denies access to therapy. Prefixing 'personality disorder' with the word 'severe' can therefore be problematic as resources become largely based on clinical classifications rather than individual service user need. 
Reviews of the efficacy of the DSPD programme have been largely inconclusive in terms of establishing clear and well-defined programme successes. 9 The heavy financial implications of providing therapy for 300 DSPD service users were cited as a potential trigger for reform. Indeed, the response to the consultation has identified a necessary re-shaping in favour of a pathway that was more efficient.1

Based on 91 responses, the Response to Offender Personality Disorder Consultation has a broad aim of addressing the needs of high-risk offenders more effectively through a collaborative working (NHS and NOMS) pathway. It is envisaged to interweave with other strategies of reducing re-offending and reducing the risk of harm to the public in addition to meeting with objectives set within contemporary mental health policy. The general objectives are as follows:

To introduce a new pathway that:

- Provides interventions and treatments earlier;

- Provides interventions in the most suitable location;

- Provides additional support to those who have completed programmes;

- Enhances ongoing supervision.

A key theme emerging from this response is the attention towards providing step-down and progression schemes within the secure estate and approved premises. The trajectory of offender personality disorder pathways and the DSPD NHS site decommissioning has been seen by some, such as the Centre for Mental Health, 10 to be encouraging. Supporters consider that largely, this re-formatting of services is a step in the right direction for greater inclusion and thus therapeutic support.

Multidisciplinary and cross-agency approaches overarch the new pathway approach. For many working in established and new environments providing services emerging from this new strategy, significant challenges may await. Problems in communication and effective collaborative practice are seen to threaten joint working initiatives. So-called 'silo' working has been cited as a common problem prohibiting effective transfer of key information between different agencies. While partnership, joint and multidisciplinary working have been formalized under legislation in the past (for example, CJA 2003), difficulties remain in the logistics of providing seamless and coordinated approaches.

The convergence of health and criminal justice is fast becoming commonplace; however, such approaches can be fraught with ideological and operational difficulty. Care and punishment occupy opposing positions on an ideological continuum. Many professions involve some level of duality in their work, for example, police officers, prison officers, psychiatrists and social workers. On the one hand they will be required to provide welfare or care; on the other, they may administer control underpinned by legislation. What may complicate this further, both for the practitioner and the recipient, is the environment or context that this exchange takes place within.

The difficulties experienced and role conflicts in the delivery of what has been remarked as 'therapeutic custody' have already been explored in the context of high-security hospitals by Burrow.11 The delivery of care within an explicit remit of control is less than desirable and has implications for the worker and the offender/patient. Rutherford12 ( p. 10) in an exploration of convergence raises caution that ' $[\mathrm{t}]$ he lines between prisons and hospitals may become overly blurred. Prisons should never be a substitute for hospitals, and hospitals should not be designed like prisons.' Onlookers may naturally gravitate towards thinking that for the treatment of diagnosis such as SPD, the secure hospital estate would be the logical course of action. However, in reality, as Edgar and Rickford13 explain, secure hospital bed availability is an ongoing problem for the prison service as transfers out of prison are often delayed or not completed in a timely or therapeutic way.

Treating personality disorder in the custody environment has previously been raised in official policy. In particular, the National Institute for Health and Clinical Excellence antisocial personality disorder guidance 14 advocates for in-depth analysis to take place over the clinical and cost effectiveness of prison-based therapeutic communities (treating personality disorder) over routine prison care. The value of such approaches nationally is unclear and the 2009 paper encourages a large-scale randomized controlled trial to be undertaken to evaluate its effectiveness and any possible harms over a number of years.

It is clear that current agendas favour therapeutic provisions in the prison environment. In an attempt to overcome the dilemmas of delivering therapy within the custody context, the offender personality disorder pathway document states that services will be commissioned based upon agreed specifications including the psychologically informed planned environments (PIPES) concept. This model aims to provide progression options for service users that allow for the testing and development of relationships and behavioural management strategies in the prison environment through enhanced key worker relationships (see Johnson and Haigh 15 for an overview of the literature). Such approaches, while innovative and potentially positive, require substantial financial investment and an availability of specially trained staff to operationalize these measures on a consistent basis. It is without doubt that the potential for such approaches to be burdened by the financial constraints that the criminal justice system currently faces is a very real proposition.

The successes of the offender personality disorder pathway lie within a number of domains and raise some critical questions. Firstly, services find themselves in a quandary. Offenders who are diagnosed and are in receipt of interventions may find themselves falling into a category of being considered as doubly deviant. They are labelled as an offender and mentally disordered and thus become the subject of judgements rooted in dominant 
Taylor, P. (2012). Severe personality disorder in the secure estate: continuity and change. Medicine, Science and the Law, 52(3), 125-127.

cultural prejudices. Conversely, those in the prison population who may be defined as having a personality disorder may not be eligible to participate in the programme as it primarily deals with SPD. Secondly, the problem persists on the nature to which parole boards and mental health review tribunals interpret risk. Those involved are semiautonomous individuals immersed in professions that are increasingly mandated, as Hotopf et al.16 describe, to act as defensive agents. They must negotiate their own interpretation of the risk and the burgeoning effects of risk discourses that pervade public, political and professional spheres.

To conclude, continuities and change are bound by political and professional discourses (such as risk minimization) and clinical/legal practices (such as care and control). Further constructive critical reflection (informed by comprehensive service evaluation and empirical research) would not go amiss before embarking upon a new era of defining and responding to those with personality disorder, offenders or otherwise.

1 Department of Health/National Offender Management Service Offender Personality Disorder Team. Response to the Offender Personality Disorder Consultation. London: Department of Health, 2011

2 House of Commons. 533 House of Commons Written Ministerial Statements 211 75WS, Hansard (21 October 2011)

3 Adshead G. Murmurs of discontent: treatment and treatability of personality disorder. Adv Psychiatr Treatt 2001;7:407-15

4 Seddon T. Dangerous liaisons; personality disorder and the politics of risk. Punishment Soc 2008;10:301-17 5 Rutherford A. Dangerous people: beginnings of a new labour proposal. In: Newburn T, Rock P, eds. The Politics of Crime Control: Essays in Honour of David Downes. Oxford: Oxford University Press, 2006:51-89

6 Harrison K. Dangerousness, Risk and the Governance of Serious Sexual and Violent Offenders. London: Routledge, 2011

7 Rose N. Governing risky individuals: the role of psychiatry in new regimes of control. Psychiatry Psychol Law 1998;5:177-95

8 Seddon T. Risk, dangerousness and the DSPD units. Prison Serv J 2008;177:27-31

9 Tyrer P, Duggan C, Cooper S, et al. The successes and failures of the DSPD experiment: the assessment and management of severe personality disorder. Med Sci Law 2010;50:95-9

10 Centre for Mental Health. Response to the PD pathway consultation from Centre for Mental Health. 2011. See http://www.centreformentalhealth.org.uk/pdfs/Response to the PD pathway consultation centre $\% 20$ for $\% 20$ mental $\% 20$ health final.docx (last checked 1 November 2011)

11 Burrow S. The special hospital nurse and the dilemma of therapeutic custody. J Adv Health Nurs Care 1991;1:2138

12 Rutherford M. Blurring the Boundaries: The Convergence of Mental Health and Criminal Justice Policy,

Legislation, Systems and Practice. London: Sainsbury Centre for Mental Health, 2010

13 Edgar W, Rickford D. Too Little too Late: An Independent Review of unmet Mental Health needs in Prison. London: Prison Reform Trust, 2009

14 National Institute for Health and Clinical Excellence. Anti-Social Personality Disorder: Treatment, Management and Prevention. London: NICE, 2009

15 Johnson R, Haigh R. Social psychiatry and social policy for the $21^{\text {st }}$ century: new concepts for new needs- the enabling environment initiative. Ment Health Soc Inclusion 2011;15:17-23

16 Hotopf M, Wall S, Buchanan A, et al. Changing patterns in the use of the Mental Health Act in England 19841996. Br J Psychiatry 2000;176:479-84 